\title{
The knowledge Theory Basis and Value Orientation of Education in Sports
}

\author{
Qiyang Zou \\ Institute of military sport, Dalian Naval Academy , Dalian,LiaoNing 116000
}

Keywords: Sports education, The basis of knowledge theory, The value orientation,

\begin{abstract}
Sports education is the narrow sense of sports, commonly known as "small sports". It is an integral part of education and is a purposeful, planned and organized process of education through physical activity and other auxiliary means. Physical education is to promote students' physical and mental health development as the goal of the school education important constituent, "health first" is the guiding ideology of school education, and sports and health has obvious relevance. This paper analyzes the knowledge theory basis of sports education and points out the value orientation of sports education.
\end{abstract}

\section{Introduction}

Education, as a unique human behavior, its connotation and form are also changing with the development of The Times. Survival experience learning, language learning, its potential excavation, self-expression and perfect, and so on are our through education, and this is the only way for us to become a social person. As an important part of education, sports education needs to be clear about its basis of knowledge theory, and its value choice is also worthy of serious discussion.

\section{The Basis of Knowledge Theory of Sports Education}

In fact, before the middle of last century, early school sports education had some humanistic education tendencies, and education personality improvement was its important goal. However, with the development of society and change, scientific physical education curriculum tend to be increasingly obvious, enhanced physique and skill of teaching becomes a school sports education major and even can be said to be the only purpose, this change reflects the physical education towards the world and adapt to the development of compromise. Since the middle of the 20th century, the role of physical fitness in the era of knowledge economy has been gradually diminishing, and the demand of various occupations for scientific knowledge has increased significantly. The skills and abilities that people acquire through sport are not as important in making a living as before, but that doesn't mean there's no market for education. As modern for the quality of life and the quality of life, sports as an important bridge to achieve the project target its unique role is being more and more people realize that sports education has become a new era, with emphasis on the quality of teaching an important part of. Then what sports the subject how to locate, its concept is how, when enhanced physique is the main way of physical education, students' physical education learning standard for determining depend mainly on physiological indexes, the sports teaching the theoretical basis of the law is mainly the function of the body, the sports education concerns remain in the ascending body strong and dissemination of technology professor motion. However, in fact, the constitution of the Chinese teenager is not as good as the Japanese and the other countries of the world, and the physical fitness of the Chinese teenager is not as good as expected, and the sports education theory and practice have been disjointed. When the education guideline of "health first" is established, it is necessary to understand the relationship between sports and health. From a psychological point of view, people's health can be divided into two aspects, one is the physical level, and the other is a psychological level, whereas in the past of that kind of pure human body physiology change rule as the sports teaching to follow the basic rule of practice is not comprehensive. As people for its development and deepening of knowledge development and the establishment of the education of "health first" guiding ideology, sports 
education important subject position to promote the development of students' physical and mental health was established, and its task is in a healthy physiological, psychological and social three aspects promote the overall development of students.

\section{The value selection of sports education}

(1) Focus on cultivating the personality of subjectivity

In modern education, students' ability development, perfect personality, creativity, play is undoubtedly the most important task, and physical education is based on the student body movement and the movement technology teaching shape the subjective personality, because of the action mechanism of the central level in neural network close contact with the mental mechanism of thinking, sports is not just about physical fitness, more to the person's intelligence and character that cannot be ignored. As is known to all, children's education is mostly carried out through some sports games, which has scientific basis. This plays a vital role in the development of children's tenacious will and the formation of perfect personality. It is also an important class for children to recognize and actively participate in interpersonal relationships. So the body cognition in sports is not limited to the carcass. Sport is a purposeful activity to shape and beautify one's body. It is the maintenance of one's body. The level of the body of the existence of a life is ignored in constitution, so the establishment of subjectivity personality cannot be replaced in the sports education, the feelings of people subject is human body in addition to as a "tool" of movement a worth highlighting. In philosophy, a function of personality is the most important feature is the subjectivity, subjectivity type characteristics of personality as a person brings together the initiative, responsibility, independence and cooperation spirit, and with or without creative spirit, creative spirit of subjectivity is the main sign. Whether it is to grasp the feelings and self judgment and evaluation, and interpersonal interaction, with benefit, team collaboration, these are all sports after subjectivity consciousness education of the students will be delighted to realize.

(2) More efforts to establish humanistic spirit

Humanism in education refers to the cultivation of students' ideals, beliefs and emotions as the main content of value orientation, rather than simply teaching various sports knowledge and actions. Movement in continually developing increasingly rich content, new sports are continuously invented, and external conditions were adapted, as in the process of human has been the subject of the active role, human beings have been beyond movement rather than passively adapt to the movement. Only when the development of physical ability and emotion is consistent, complete personality can be formed, which is the focus of humanistic sports. Sport itself is a physical activity education aimed at the overall development of people, rather than a means of training people into something. The modernization of society makes sports break through some secular cognition and gradually become a part of culture. The modernization of society calls for the modernization of education, and educated from various perspectives are the main body of high level training is the requirement of modern education, so both general education and various disciplines, including physical education, education concept should be continuously updated. Body, skills and personality are all the objects of education in sports. Both students' body and personality should be developed into the realm of beauty in scientific and orderly sports education. At the same time, the absorption of aesthetic nutrition can enrich the content and thoughts of education and promote the physical and mental health of students. People in the understanding of itself as well as research on the demand of itself will be with the progress of science and technology and accelerating, but in such a big background, the sports education scale as directly affect the human physical and mental health of its value must be continuously emerging, at the same time the human civilization will also because of physical education in the sports culture Angle of continuous function and continuous development.

(3)Set up the concept of lifelong sports

The development of modern society requires high quality talents with healthy body and health, and lifelong sports make sports accompany people for a lifetime. This is the trend of sports development in the world. It is the general trend to deepen sports reform and establish a lifelong sports system. The part of the term "life sports" is that the journey from the beginning to the end of 
the human life is a constant exercise in physical exercise, which is an essential part of the human life, and the purpose of it is clear. On the other hand, lifelong sports can provide opportunities for people to participate in physical exercise at different times and in different fields. The systematization and integration of sports are its goals.

(4) The general trend of sports education industrialization

Under the condition of market economy, national school education is no longer the only investor, government, undertake to the student recruitment and uniform distribution, the government control of the situation of all education activities has been broken, the school has become a kind of give priority to with the productive consumption and production in a body's education of industrial organization, it faces the society, run independently and has the legal person status. With the industrialization of education, the industrialization development of education, as one of its components, is inevitable. Under the condition of market economy, education began to be industrialized, and people's lifestyle and values are also changing. Spending money on health is no longer an incomprehensible activity, but rather a rather advanced concept of consumption. In some universities in China, many students pay learning yourself interested in sports, this is paid teaching has gradually formed pattern of diversity in content of sports teaching, physical education has a place in personnel training system, also began to have the input and output. Sports education industrialization is the requirement of market economy, is a scientific, reasonable and keep up with the demand of The Times, it is an integral part of economic foundation, but also can be missing part of the third industry, but it will not change attributes of universal education, it is still an important part of the superstructure. Industrialization and paid for the education of physical education were improved in different degrees of sports education proceeds to expand the education tolerance, at the same time these will effect on physical education environment, so in the process of physical education industry development must pay attention to eliminate the influence of interest for its healthy development.

\section{Conclusion}

People more and more aware of the sports is to improve the human life and is an important basis and guarantee of the quality of life, the unique role of sports in the modern society and the importance is increasingly prominent, in the education of many aspects, mutual penetration and coordinated development, promote the students' all-round development and healthy growth. Physical education is a along with The Times and social development, gaining new meaning and contents of the subject, its value orientation should be should be based on the analysis of the theory of knowledge determine, under the premise of maximum limit for social development and make contribution to the improvement of people's life quality.

\section{References}

[1] Jiandong Zhou. Sports and knowledge -- an investigation based on the knowledge theory of sports education [J]. Journal of sport, 2017, (2):1-7.

[2] Wei Gao. Analysis on basic knowledge of education in sports [J]. Contemporary sports technology, 2012, (4):95-99.

[3] Yongchun Tang. How to increase the value orientation of sports education [J]. Modern education science (higher education research), 2003, (6):89-90.

[4] Rongbing Yin. Basic education school physical education curriculum content selection and value orientation evolution and appeal [J]. Journal of wuhan sports university, 2017, (2):81-85.

The dalian naval academy scientific research and development funds 
About the author:

The first author, Qiyang Zou, male, born on October 10, 1989, native place: Zhumadian city, Henan province, education background: master, title: lecturer, research direction: education training and practice of sports. 